Thorax (1975), 30, 54.

\title{
Re-expansion pulmonary oedema
}

\author{
M. W A Q A R UDD IN a nd A. BER NSTEIN
}

Department of Thoracic Medicine, Hope and Ladywell Hospitals, Salford M6 8HD

\begin{abstract}
Waqaruddin, M. and Bernstein, A. (1975). Thorax, 30, 54-60. Re-expansion pulmonary oedema. Clinical details are given of two patients who developed ipsilateral pulmonary oedema following re-expansion of their spontaneous pneumothoraces by intercostal drainage of air. The possible mechanisms underlying the oedema are discussed, and prior literature is analysed. Reference is made particularly to its predictability and to precautions recommended to minimize the frequency of this potentially fatal complication in the management of spontaneous pneumothorax.
\end{abstract}

\section{CASE REPORTS}

CASE 1. A 21-year-old man was admitted to Ladywell Hospital on 13 February 1973. Five weeks prior to admission he had had an influenzalike illness associated with cough, sputum production, and dyspnoea. His general condition improved after one week, but his dyspnoea persisted and became gradually worse on exertion. There was no history of chest pain nor any past history of chest disease.

On examination he was comfortable at rest. The heart rate was regular at 80 beats per minute, and blood pressure $130 / 80 \mathrm{mmHg}$. The physical signs suggested left-sided pneumothorax, and a chest radiograph confirmed this, showing complete left-sided pulmonary collapse with some mediastinal shift towards the right side (Fig. 1). On the following day an intercostal tube was inserted in the second left intercostal space anteriorly on the left side and a Heimlich valve was attached to the distal end of the catheter. An immediate egress of air through the valve was observed. Within minutes the patient had a bout of severe coughing productive of small amounts of clear sputum. His cough persisted, and although there was no deterioration in his general condition, his sputum showed a pink discolouration within ten minutes. Examination at this stage revealed fine crepitations audible over the left middle and lower chest. An anteroposterior chest radiograph taken one hour after intubation showed almost complete expansion of the left lung but with an homogenous infiltration involving the left middle and lower zones (Fig. 2). Within two hours of intubation he appeared pale and anxious with tachypnoea, sweating, and a tachycardia of 100 beats per minute. His blood pressure fell to $90 / 60 \mathrm{mmHg}$. A pink serous fluid $\vec{\varphi}$ was seen to be draining from the intercostal tube of and this was therefore reconnected to an underwater seal system because of the possibility of blockage of the Heimlich valve cusps. His general condition improved spontaneously over the next 24 hours, and during this period about one litre of serous fluid drained into the underwater seal $\stackrel{\mathbb{Q}}{\Omega}$ bottle. Serial chest radiographs over the follow- $\overrightarrow{\overrightarrow{0}}$ ing five days showed clearing of the pulmonary 3 infiltration. Within six days his radiograph returned to normal (Fig. 3) and the intercostal tube was removed on the seventh day. Full expansion was maintained thereafter. He was discharged on 2 March 1973 and has subsequently remained symptom-free.

CASE 2. A 24-year-old man was admitted to $\stackrel{\circ}{3}$ Ladywell Hospital on 28 August 1973. Three days 0 prior to his admission he developed left-sided chest pain of sudden onset accompanied by dyspnoea. There was no previous history of chest disease.

On examination he was dyspnoeic at rest. He o had signs suggesting a left-sided pneumothorax, $N$ and a chest radiograph confirmed this, showing N almost complete pulmonary collapse with some $\sigma$ mediastinal shift towards the right side (Fig. 4). An intercostal tube was inserted in the fifth left intercostal space in the anterior axillary line, and $\stackrel{\oplus}{\oplus}$ a Heimlich valve was attached to the distal end of the catheter. An immediate egress of air through the valve was observed. The patient's $\mathbb{\mathbb { D }}$ dyspnoea was considerably relieved, but within three hours crepitations were audible over the left lung posteriorly, and an anteroposterior chest 


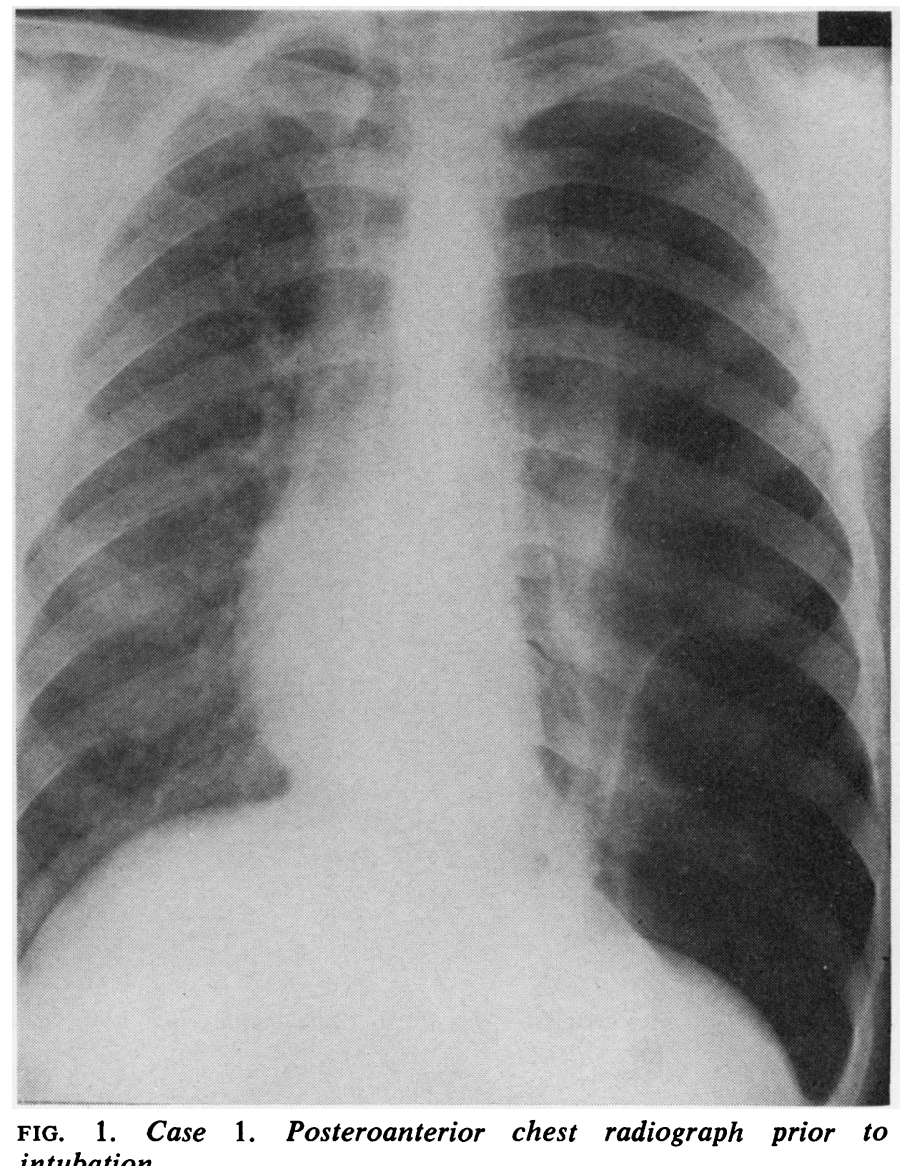

intubation.

radiograph taken at this time showed a fully expanded left lung, though with diffuse shadowing throughout the whole lung field, excluding only the apical region (Fig. 5).

Serous fluid was seen draining from the intercostal tube, and therefore the drainage system was changed to an underwater seal system. The patient's condition did not deteriorate at any time, and by the fifth day there was complete radiological clearing of the left lung. Extubation was performed and the lung remained fully expanded (Fig. 6). He was discharged on 4 September 1973.

He was re-admitted to another hospital on 26 September 1973 with a further complete leftsided pneumothorax. Intercostal drainage to underwater seal was carried out, and although satisfactory expansion was achieved, initial chest radiographs showed pulmonary infiltration, which again spontaneously resolved.

\section{DISCUSSION}

The earliest accounts of pulmonary oedema occurring in a re-expanded lung are those of Foucart in 1875 and Ortner in 1899-both cited by Carlson et al. (1959) - and of Riesman (1902). The oedema followed aspiration of large volumes of pleural fluid. In 1906 Hartley reported 35 similar cases all occurring within one hour of thoracocentesis.

Carlson et al. (1959) first reported this complication following re-expansion of the collapsed lung due to pneumothorax, and since then 11 further cases including the present report have been described (see Table). 


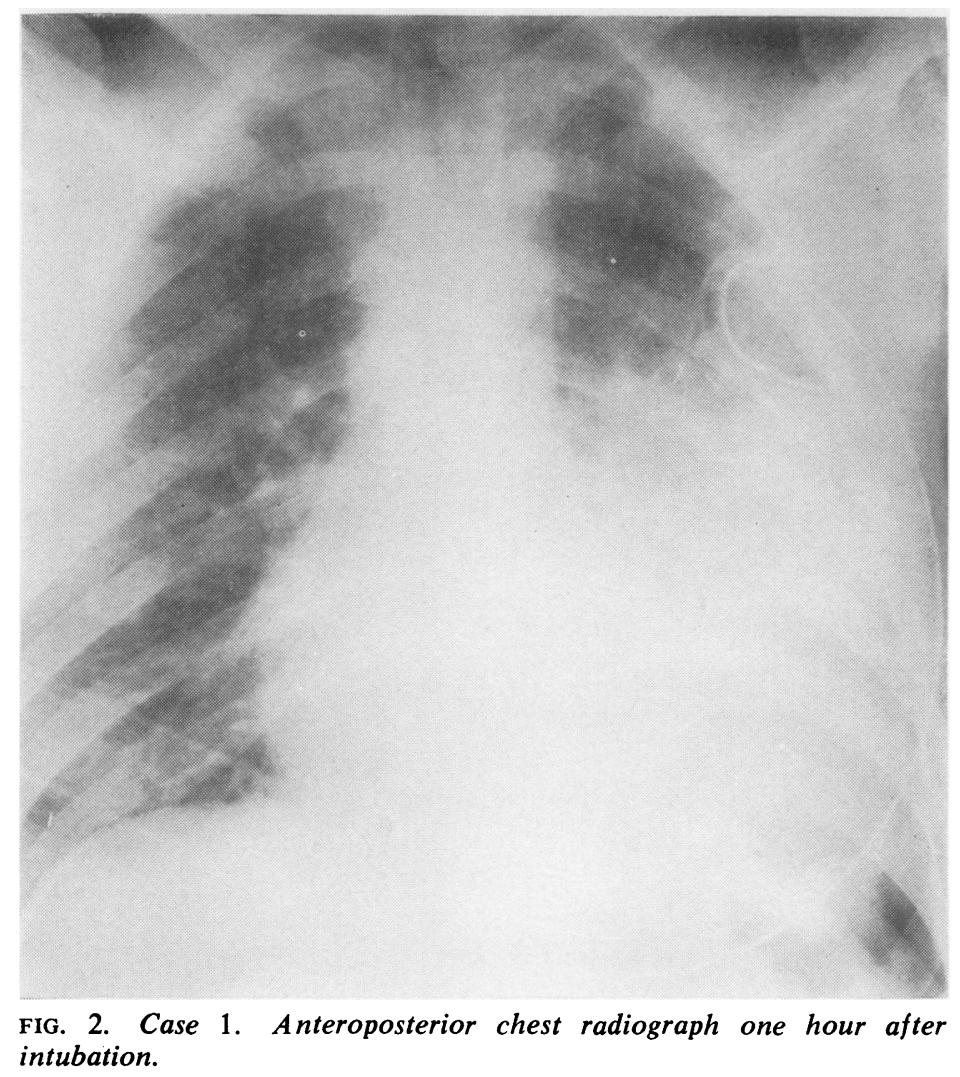

Early evidence of pulmonary oedema may be the occurrence of cough and chest tightness during or immediately after aspiration of air (Trapnell and Thurston, 1970), as happened in case 2, and in cases described by Childress, Moy, and Mottram (1971), Ratcliff et al. (1973), and Saini (1974). It is generally agreed that oedema is more likely to occur as a complication of large pneumothoraces and where collapse has been prolonged for a period of at least three days (Trapnell and Thurston, 1970; Sautter et al., 1971). In the 12 cases recorded, the duration of pneumothorax (from onset of dyspnoea) averaged 18 days with a minimum of three days, apart from one patient (Humphreys and Berne, 1970) with metastatic carcinoma in whom the pneumothorax apparently complicated an attempt to place a central venous pressure catheter percutaneously, and which was re-expanded within one hour of this accident.

The fact that negative pressure was applied to the pleural cavity in no less than five of the $12:$ cases reported suggests that the rapidity with 3 . which air is removed from the pleural cavity is a $\delta$ second predetermining factor.

Miller et al. (1973) emphasize both these points 0 in their experiments on Rhesus monkeys. They found ipsilateral pulmonary oedema within two hours in all monkeys with induced 80 to $100 \% \frac{\vec{N}}{\mathrm{~N}}$ pneumothoraces where the pneumothorax had $\mathrm{N}$ been maintained for three days and where rapid $N$ re-expansion was obtained by applying suction of $\mathrm{N}_{\mathrm{J}}$ $-10 \mathrm{cmHg}$. In contrast to these, pulmonary 0 oedema did not develop in two other groups of monkeys:

(a) where underwater drainage alone was ap- $\stackrel{\oplus}{\rightarrow}$ plied after three days' collapse, and

(b) when the lung was re-expanded after one hour with the application of negative pressure to the intrapleural cavity.

There have been several theories as to the pathogenesis of the oedema; all are conjectural, 


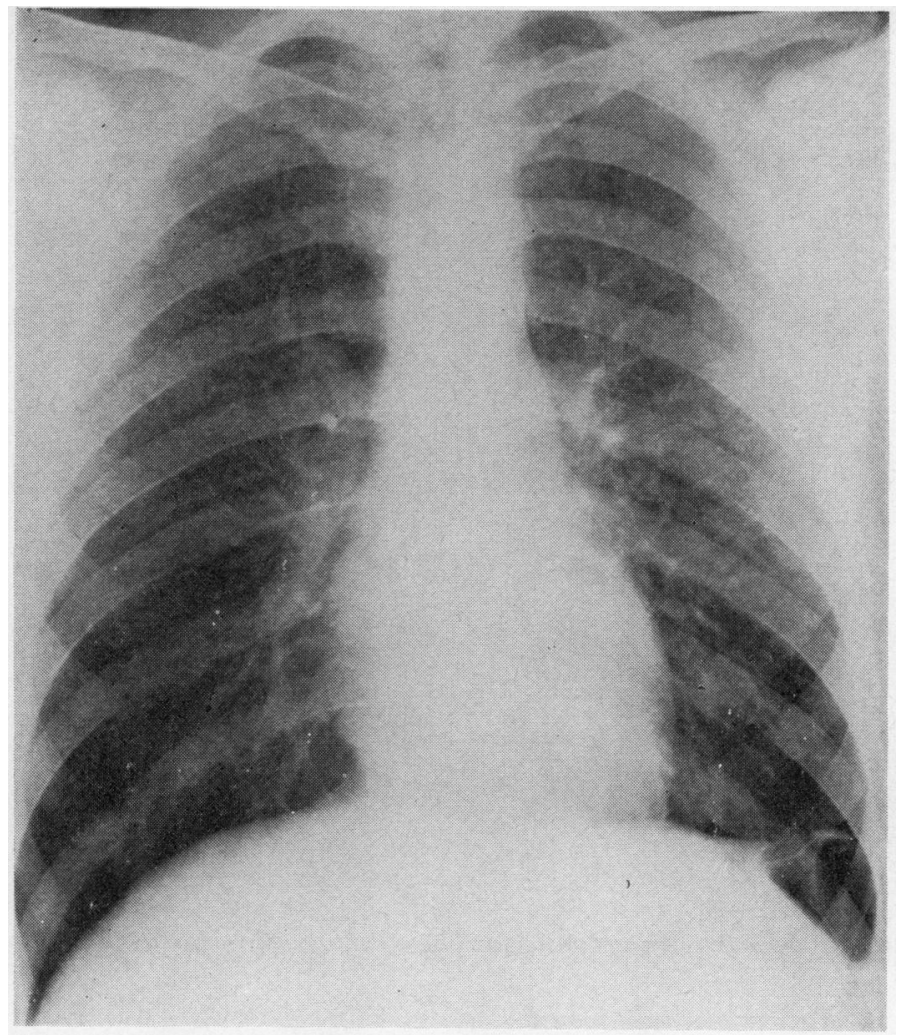

FIG. 3. Case 1. Posteroanterior chest radiograph. Post-extubation film.

and it is probable that all are, to some extent, involved. It is possible, as suggested by Carlson et al. (1959) and Humphreys and Berne (1970), that anoxic damage to the pulmonary capillary endothelial cells during collapse is followed by increased permeability of these capillaries to fluid after expansion of the lung and restoration of the pulmonary circulation. There is certainly evidence that capillaries deprived of oxygen for three minutes show an increased permeability to protein (Barach, Martin, and Eckman, 1938).

A second explanation, possibly acting in concert with anoxic capillary damage, is the effect on these capillaries of a sudden and large increase in negative intrapleural pressure which occurs with rapid pulmonary expansion, especially with the aid of suction applied to the pleural cavity. Warren, Peterson, and Drinker (1942) demonstrated in dogs that a large increase in negative intrathoracic pressure drew fluid from pulmonary capillaries into parenchyma, and, under excessive conditions, not only plasma but red cells left the capillaries. Robin, Cross, and Zelis (1973), in their comprehensive review of pulmonary oedema, also drew attention to this factor.

Finally there is the inevitable consideration of the effect of alteration of surface tension. Several authors (Trapnell and Thurston, 1970; Sautter et al., 1971) suggest that decrease of surfactant in the chronically collapsed lung, with a consequent rise in alveolar surface tension, may be a contributory factor. However, it has been shown that pulmonary oedema is not usually associated with abnormally high alveolar surface tension forces, and that oedema can develop in a degassed lobe without an air-liquid interface (Robin et al., 1973).

With respect to technique, we originally were concerned that the use of the Heimlich valve (Bernstein, Waqaruddin, and Shah, 1973) may 


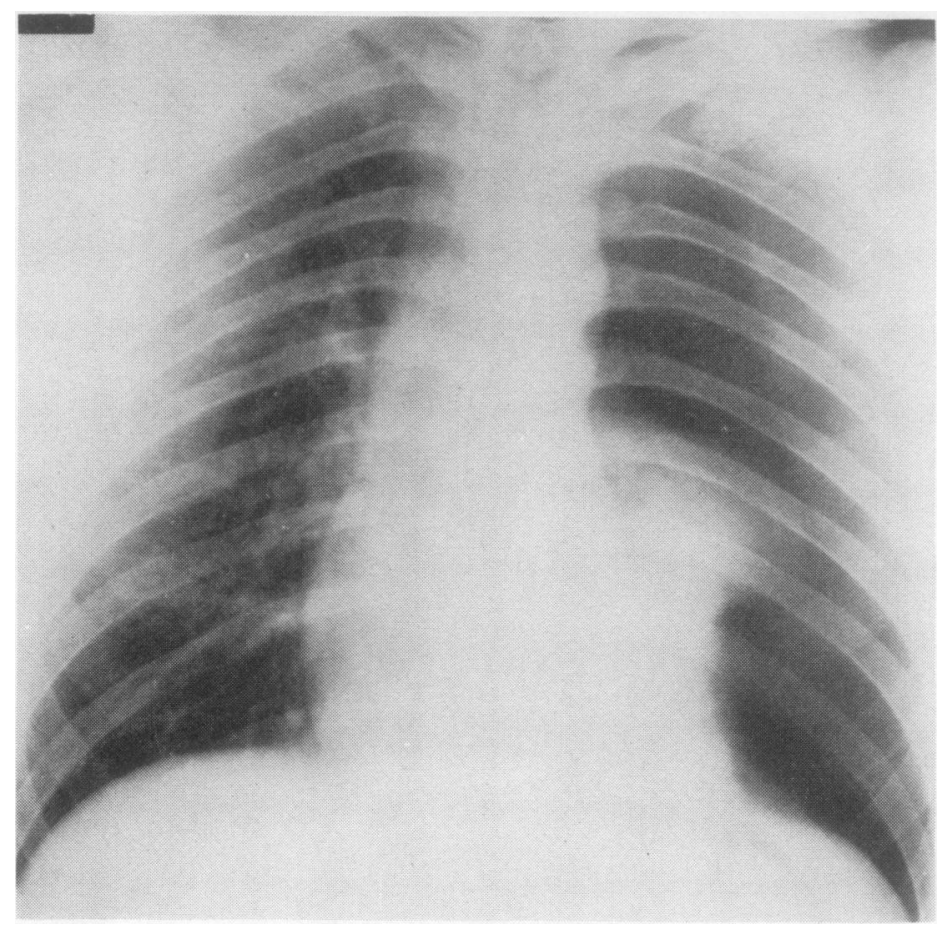

FIG. 4. Case 2. Anteroposterior chest radiograph prior to intubation.

have been a causative factor in the production of oedema because of the rate of egress of air using this method. This fear appears to be obviated by the recurrence of ipsilateral oedema in case 2 during his second admission when the pneumothorax was drained to an underwater seal. There is the possibility that, for some reason, this patient may have been prone to develop pulmonary oedema. The other lung, however, showed no radiological abnormality; plasma proteins were normal, and examination of the heart and electrocardiogram were also normal. Further lung function tests were not performed.

Whatever the mechanisms involved, it seems that the development of pulmonary oedema is a relatively benign complication, although two fatalities and one near fatality have been recorded. The case of Trapnell and Thurston (1970) was an 18-year-old boy with impaired intelligence who exhibited a number of congenital abnormalities, including webbing of the toes and pigeon chest. Following a three-day history of chest pain and dyspnoea he was found to have a left-sided pneumothorax with complete collapse of the lung. Underwater drainage failed to produce expansion, and suction was applied with a Roberts pump. Severe pulmonary oedema developed in the left lung within four hours. In spite of in- $x$ tensive therapy he died about seven hours after 3 thoracocentesis.

Sautter et al. (1971) gave details of a 69-year- 을 old man with a large right-sided pneumothorax of 21 days' duration. He had a past history of hypertension and aortic incompetence with manyo episodes of left ventricular failure. The lung expanded satisfactorily following drainage, but within one hour he was found to be severely dis- $N$ tressed and cyanosed. Unilateral pulmonary oedema was demonstrated radiologically, and $\bar{\sigma}$ death occurred 24 hours later despite intensive resuscitative measures.

The patient described by Ratcliff et al. (1973) $\cong$ survived only with the help of intensive therapy, including mechanical ventilation with positive ${ }^{\circ}$ end-expired pressure.

Pulmonary oedema occurs more commonly $\frac{\stackrel{\rho}{\Phi}}{\mathbb{Q}}$ than the dearth of reports would appear to indi- $\varrho$ cate. The three episodes described occurred over 
FIG. 5. Case 2. Anteroposterior chest radiograph three hours after intubation.
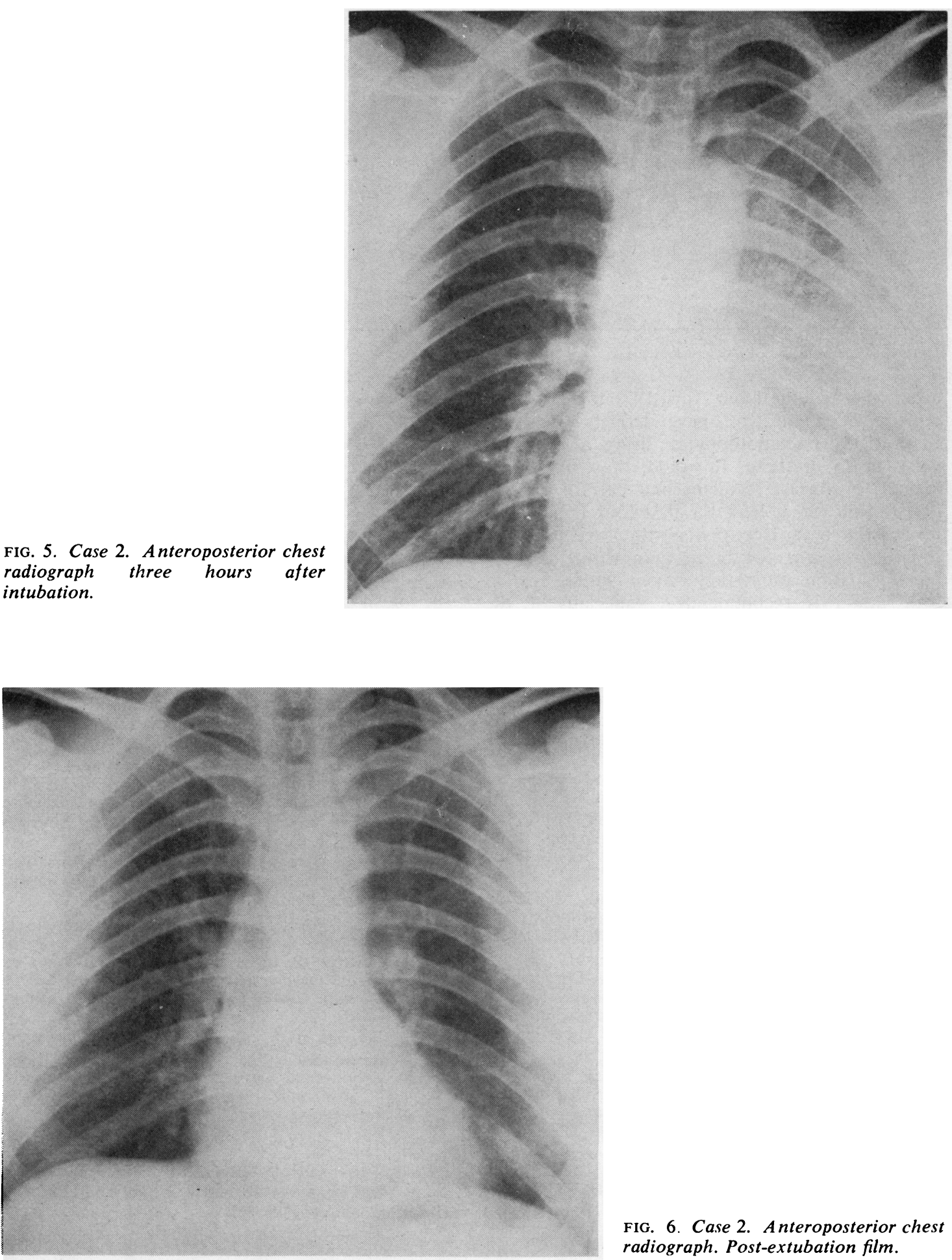

FIG. 6. Case 2. Anteroposterior chest radiograph. Post-extubation film. 
T A B L E

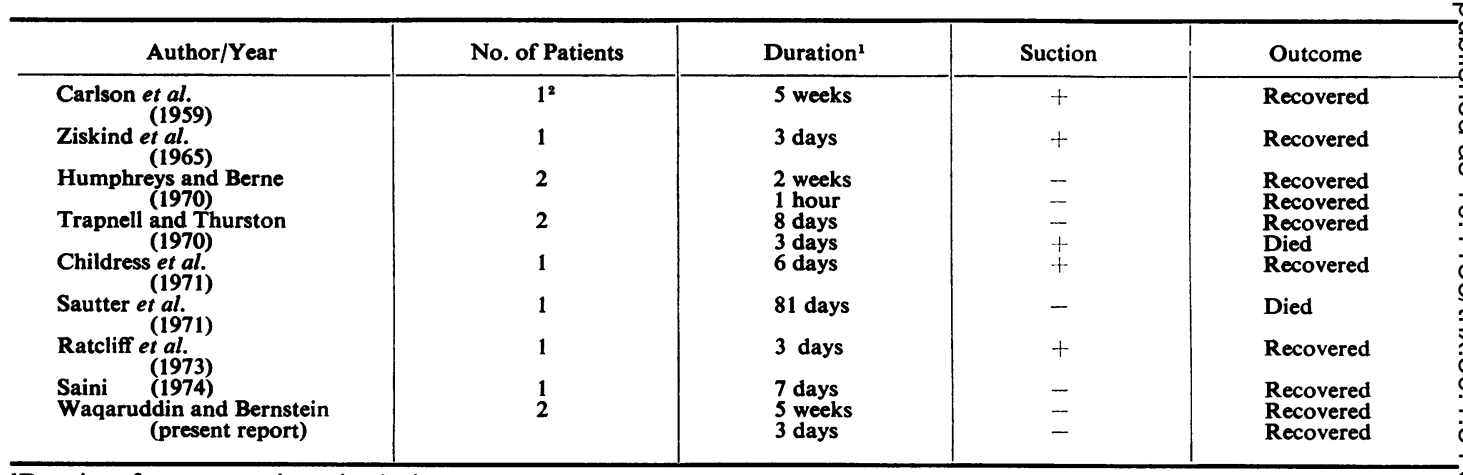

${ }^{1}$ Duration of symptoms prior to intubation.

${ }^{2}$ Five cases mentioned, only one described in detail.

a period extending from April 1971 to May 1974, during which time we have actively treated a total of 34 pneumothoraces, using a Heimlich valve in 25 of these. It would, therefore, seem logical to suggest frequent and careful clinical observation for at least the first four hours after intubation in those patients with large pneumothoraces present for more than three days. A post-intubation radiograph taken within two to four hours is recommended, especially if the application of suction is considered necessary.

It may well be worth while controlling the removal of air by means of a gate clamp applied proximally to the underwater bottle or, if a Heimlich valve is used, attached to a tube connected to the distal end of the valve.

\section{REFERENCES}

Barach, A. L., Martin, J., and Eckman, H. (1938). Positive pressure respiration and its application to the treatment of acute pulmonary edema. Annals of Internal Medicine, 12, 754.

Bernstein, A., Waqaruddin, M., and Shah, M. (1973). Management of spontaneous penumothorax using a Heimlich flutter valve. Thorax, 28, 386.

Carlson, R. I., Klassen, K. L., Gollan, F., Gobbel, W. G. Jr., Sherman, D. E., and Christensen, R. O. (1959). Pulmonary oedema following the rapid re-expansion of a totally collapsed lung due to a pneumothorax: a clinical and experimental study. Surgical Forum, 9, 367.

Childress, M. E., Moy, G., and Mottram, M. (1971). Unilateral pulmonary edema resulting from treatment of spontaneous pneumothorax. American Review of Respiratory Disease, 104, 119.

Hartley, P. H-S. (1906). Albuminous expectoration following paracentesis of the chest. St. Bartholomew's Hospital Reports, 41, 77.

Humphreys, R. L. and Berne, A. S. (1970). Rapid re-expansion of pneumothorax. Radiology, 96® 509.

Miller, W. C., Toon, R., Palat, H., and Lacroix, J@ (1973). Experimental pulmonary edema following re-expansion of pneumothorax. American Reviewe of Respiratory Disease, 108, 654.

Ratcliff, J. L., Chavez, C. M., Jamchuk, A., Forestner J. E., and Conn, J. H. (1973). Re-expansiom pulmonary edema. Chest, 64, 654.

Riesman, D. (1902). Albuminous expectoration follow ing thoracentesis. American Journal of Medica? Science, 123, 620.

Robin, E. D., Cross, C. E., and Zelis, R. (1973) Pulmonary edema. The New England Journa? of Medicine, 288, 239 and 292.

Saini, G. S. (1974). Unilateral pulmonary oedema after drainage of spontaneous pneumothorax: British Medical Journal, 1, 615.

Sautter, R. D., Dreher, W. H., MacIndoe, J. H.음 Myers, W. O., and Magnin, G. E. (1971). Fatak pulmonary edema and pneumonitis after reo expansion of chronic pneumothorax. Chest, 602 399.

Trapnell, D. H. and Thurston, J. G. B. (1970)극 Unilateral pulmonary oedema after pleuraf aspiration. Lancet, 1, 1367.

Warren, M. F., Peterson, D. K., and Drinker, C. K市 (1942). The effects of heightened negative pressure in the chest, together with further ex periments upon anoxia in increasing the flow of lung lymph. American Journal of Physiology 137, 641 .

Ziskind, M. M., Weill, H., and George, R. A. (1965) Acute pulmonary edema following the treatmen of spontaneous pneumothorax with excessive negative intrapleural pressure. American Revier of Respiratory Diseases, 92, 632.

Requests for reprints to: Dr. A. Bernstein, Depart覀 ment of Thoracic Medicine, Hope and Ladywe Hospitals, Salford M6 8HD. 